\title{
A comparison of rainfall measurements from multiple instruments
}

\author{
X. C. Liu, T. C. Gao, and L. Liu \\ College of Meteorology and Oceanography, PLA University of Science and Technology, Nanjing, China \\ Correspondence to: L. Liu (dll@ live.ca)
}

Received: 3 December 2012 - Published in Atmos. Meas. Tech. Discuss.: 16 January 2013

Revised: 18 May 2013 - Accepted: 25 May 2013 - Published: 2 July 2013

\begin{abstract}
Simultaneous observations of rainfall collected by a tipping bucket rain gauge (TBRG), a weighing rain gauge (WRG), an optical rain gauge (ORG), a present weather detector (PWD), a Joss-Waldvogel disdrometer (JWD), and a 2-D video disdrometer (2DVD) during January to October 2012 were analyzed to evaluate how accurately they measure rainfall and drop size distributions (DSDs). For the longterm observations, there were different discrepancies in rain amounts from six instruments on the order of $0 \%$ to $27.7 \%$. The TBRG, WRG, and ORG have a good agreement, while the PWD and 2DVD record higher and the JWD lower rain rates when $R>20 \mathrm{~mm} \mathrm{~h}^{-1}$, the ORG agrees well with JWD and 2DVD, while the TBRG records higher and the WRG lower rain rates when $R>20 \mathrm{~mm} \mathrm{~h}^{-1}$. Compared with the TBRG and WRG, optical and impact instruments can measure the rain rate accurately in the light rain. The overall DSDs of JWD and 2DVD agree well with each other, except for the small raindrops $(D<1 \mathrm{~mm})$. JWD can measure more moderate-size raindrops $(0.3 \mathrm{~mm}<D<1.5 \mathrm{~mm})$ than 2DVD, but 2DVD can measure more small-size raindrops $(D<0.3 \mathrm{~mm})$. 2DVD has a larger measurement range; more overall raindrops can be measured by 2DVD than by JWD in different rain rate regimes. But small raindrops might be underestimated by 2DVD when $R>15 \mathrm{~mm} \mathrm{~h}^{-1}$. The small raindrops tend to be omitted in the more large-size raindrops due to the shadow effect of light. Therefore, the measurement accuracy of small raindrops in the heavy rainfall from 2DVD should be handled carefully.
\end{abstract}

\section{Introduction}

Measurements of precipitation have been widely applied in meteorology, hydrology, and environmental, agricultural, and soil sciences. There are many instruments available to measure precipitation; the conventional rain gauge is the most widely used instrument worldwide, which can only measure the precipitation intensity and duration. With the development of optical and electronic techniques since the 1970s, a variety of instruments based on different principles have been developed, which can measure the size, shape, and velocity of precipitation particles. In particular, disdrometers that can measure the drop size distributions (DSDs) have been widely used in the cloud modeling and climate studies, rainfall estimation from radar, hydrological modeling, soil erosion, etc. Although the comparative observations with the disdrometers and rain gauge verify the accuracy of rain rate measured by disdrometers, there is no reference instrument that can obtain the true values, nor a standard environment that can simulate the precipitation. The DSD, number concentration, and other micro-physical variables of precipitation measured by different instruments show different discrepancies (Chandrasekar and Gori, 1991; Tokay et al., 2001, 2003; Löhnert et al., 2011), which makes the effective application of micro-physical data of precipitation difficult.

At present, the Joss-Waldvogel disdrometer (JWD) (Joss and Waldvogel, 1967), 2-D video disdrometer (2DVD) (Kruger and Krajewski, 2002), and OTT PARSIVEL disdrometer (Battaglia et al., 2010) are the most widely used disdrometers for comparisons and validations of weather radar (Sheppard and Joe, 1994; Schuur et al., 2001; Thurai et al., 2009) and Tropical Rainfall Measuring Mission (Baquero et al., 2005; Wolff et al., 2005), but the accuracy of measurements is still under examination. Observations from aboveground rain gauges and collocated buried gauges demonstrated that the wind effect can cause the underestimation of rain rate on the order of $2 \%$ to $10 \%$, which is associated with the measurement of rainfall, its drop size distribution, and wind speed at gauge rim height (Sieck et al., 2007). There are significant discrepancies in rainfall amounts from 
JWD and rain gauges on the order of $10 \%$ to $20 \%$ (Sheppard and Joe, 1994; Tokay et al., 2003), and the JWD underestimated the number concentration of small drops (Caracciolo et al., 2002). The 2DVD had a better agreement with the rain gauges, but it underestimated small to medium drops (Tokay et al., 2001). The 2DVD and OTT PARSIVEL disdrometer had close agreement in DSD parameters when $R$ was less than $20 \mathrm{~mm} \mathrm{~h}^{-1}$, while the mass-weighted mean diameter, the standard deviation of the mass spectrum, and the rain rate of PARSIVEL were higher than those of 2DVD when rain rate was particularly above $30 \mathrm{~mm} \mathrm{~h}^{-1}$ (Thurai et al., 2011). A combination of the JWD and 2DVD can meet the requirement for accurate sampling of the entire drop size spectrum (Tokay et al., 2013).

In order to evaluate the accuracy of rainfall measurements from different instruments based on different principles (especially the DSDs), we analyzed the rainfall observations collected during the Atmospheric Radiation Measurement (ARM) Climate Research that was operated at Darwin, Northern Territory, Australia, from January to October 2012. The rainfall observations are from a tipping bucket rain gauge, a weighing rain gauge, an optical rain gauge, and a present weather detector. The DSD observations are from a Joss-Waldvogel disdrometer and a 2-D video disdrometer. In this paper, a brief description of each instrument can be found in Sect. 2. Section 3 summarizes the general rainfall events; overall comparisons of rain amount and rain rate from different instruments are analyzed, and selected events are analyzed in details minute by minute. Parameters of drop size distribution observed by JWD and 2DVD are calculated and compared, and their characteristics and differences are discussed. Conclusive remarks are given in the last section.

\section{Instrument description}

\subsection{Rain gauge}

The tipping bucket rain gauge (TBRG for short) is a siphoncontrolled tipping bucket rain gauge (RIMCO 7499 series). Any rain falling on the collecting funnel is directed through a siphon control unit and discharges as a steady stream into a two-compartment bucket mounted in unstable equilibrium. The volume of each compartment bucket is equivalent to a rainfall of $0.2 \mathrm{~mm}$. Therefore, the precision and resolution is one full bucket $(0.2 \mathrm{~mm})$, the accuracy $\pm 1 \%$ at rainfall intensities up to $250 \mathrm{~mm} \mathrm{~h}^{-1}$, and $\pm 3 \%$ at rates up to $500 \mathrm{~mm} \mathrm{~h}^{-1}$. The main source of the TBRG sampling error is its sampling principle and its inability to capture the small temporal variations during the rainfall time series (Habib et al., 2001). There are substantial errors in the 1 min estimates especially at low rain rate: as the timescale of the rainfall increases, the error decreases substantially (Wang et al., 2008).

The weighing rain gauge (WRG for short) operates on the principle of weighing the rainwater collected by the buckets.
The rain rate can be calculated by the difference in rainwater accumulation over a given time interval. The accuracy of the rain rate is related to the precision of the water accumulation measurement, the rate at which rainwater drains from the catchment basin into the measurement chamber, and the sampling interval (Nystuen, 1999). However, rainfall measurement is invalid during the collecting pan drains when the collecting pan fills with water. Both the TBRG and WRG are equipped with an optional heater, whereas the TBRG and WRG were not heated because the environment temperature was higher than $20^{\circ} \mathrm{C}$ in this study.

The optical rain gauge (ORG for short) measures the scintillation of infrared light produced by the liquid water drops falling between a light source and a receiver (Nystuen et al., 1996). The variation of light intensity caused by a given drop is a function of drop size, fall velocity, shape, and coherence of the light source. However, limited by the measurement principle, the ORG should not be used for frozen precipitation particles. The model ORG- 815 has a precision of $0.1 \mathrm{~mm}$ and an uncertainty of $\pm 0.1 \mathrm{~mm} \mathrm{~h}^{-1}$ in this study. Compared with the other gauges, the ORG overestimates rain rate when there are more small-size drops, and underestimates rain rate when there are more large-size drops, while it might be biased high during higher winds (Nystuen, 1999).

\subsection{Present weather detector}

The present weather detector (PWD for short) is a multivariables sensor for automatic weather observing systems. The model Vaisala PWD22 combines an optical sensor, a capacitive device Vaisala RAINCAP ${ }^{\circledR}$ rain sensor with doubleplate, and a Pt100 thermistor (2004). The optical sensor uses the principle of forward scattering for measurements of visibility and precipitation amount and type, which consists of an optical transmitter and receiver. The transmitter emits pulses with a wavelength of $875 \mathrm{~nm}$ at a frequency of $2 \mathrm{kHz}$. The receiver measures the intensity of the light that is scattered in the sample volume (approximately $100 \mathrm{~cm}^{3}$ ) at an angle of $45^{\circ}$. The signals produced by the forward scattering from precipitation hydrometeors and suspended particles are analyzed to estimate the precipitation type and rate and obstruction to vision and visibility (Lonnqvist and Nylander, 1992). The capacitive sensor RAINCAP ${ }^{\circledR}$ measures the presence and amount of water on its surface. The signal is dependent on the thickness of the water on the sensor, which is a measure of the liquid water content of the precipitation. The fallen precipitation can be removed quickly from the sensor because it consists of two slanted detectors (Haij, 2007). The Pt100 thermistor is used to monitor the temperature, as an adjustable parameter for classification of precipitation types.

These three independent measurements together provide prevailing visibility, precipitation, and present weather type. The precipitation intensity is based on both the optical and capacitive measurements. The capacitive intensity is higher than the optical intensity in liquid precipitation. PWD 


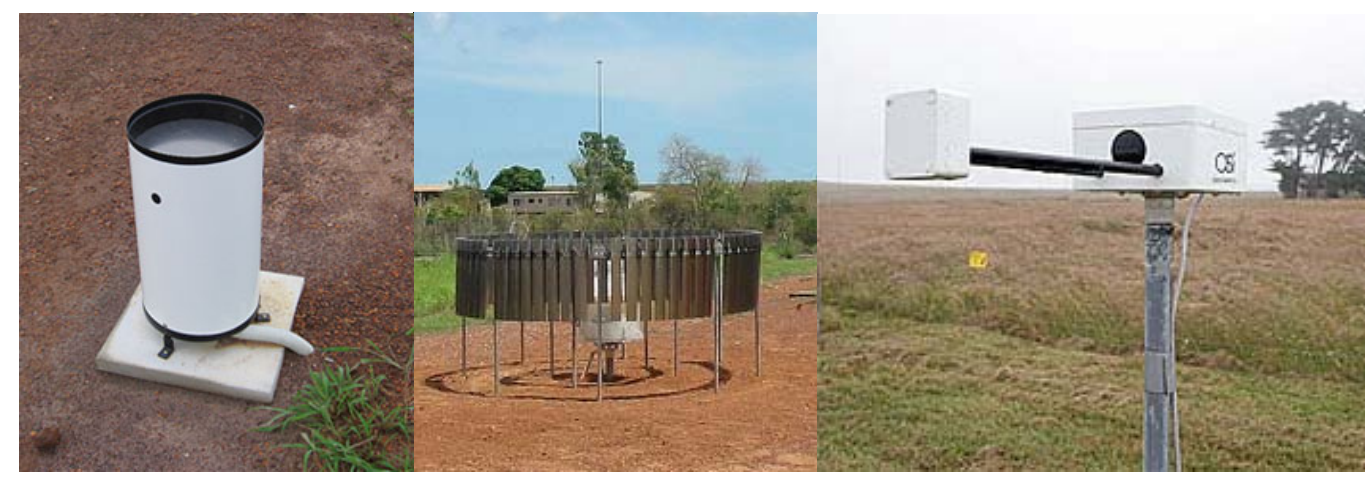

(a) Tipping bucket rain gauge (b) Weighing bucket rain gauge

(c) Optical rain gauge

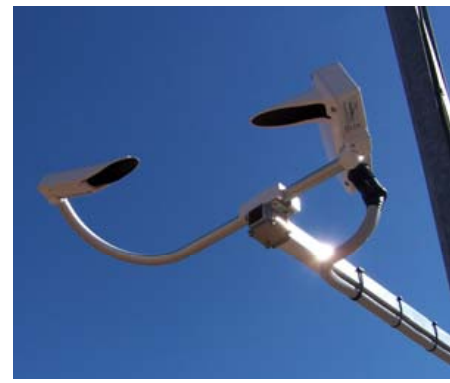

(d) Present weather detector

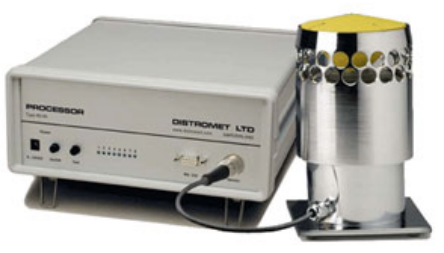

(e) Joss-Waldvogel disdrometer

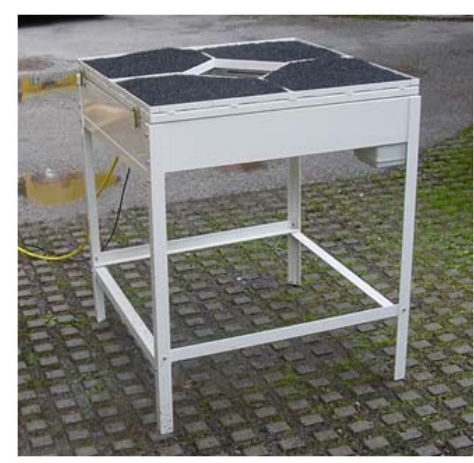

(f) 2D video disdrometer

Fig. 1. Instruments for precipitation.

multiplies the optical intensity with a scaling factor to get the water equivalent intensity in frozen precipitation. However, if the relative humidity of air is more than about $70 \%$, the surfaces could produce a signal even with no precipitation, which produces false precipitation; also the PWD might overestimate the precipitation intensity during higher winds.

\subsection{Joss-Waldvogel disdrometer}

The Joss-Waldvogel disdrometer (JWD for short) was originally developed by Joss and Waldvogel (1967) to measure radar reflectivity (Tokay et al., 2003), which is an impact type device and measures the drop size with a Styrofoam ${ }^{\circledR}$ cone with a sampling cross-sectional area of $50 \mathrm{~cm}^{2}$. It is considered to be a reference instrument in measuring the DSD at the ground. Basically the JWD transforms the energy of falling drops into electric current (Salles and Creutin, 2003). The JWD infers the size of the individual drops from the measured impact velocity of the drops through an empirical nonlinear relationship between fall velocity and drop diameter in still air (Joss and Waldvogel, 1977). The model RD-80 was used in this study. The drops are sorted into 20 size intervals ranging from $0.3 \mathrm{~mm}$ to $5.4 \mathrm{~mm}$, and the boundaries of each channel increase with drop size from $0.1 \mathrm{~mm}$ to $0.5 \mathrm{~mm}$.
It should be noted that the accuracy of JWD is sensitive to background noise; it could underestimate the small raindrops in heavy rain when the Styrofoam cone is hit by many more drops (Tokay et al., 2001). Since the largest size of the JWD is $5.4 \mathrm{~mm}$, any drops larger than $5.4 \mathrm{~mm}$ would be counted in the largest size, which causes an underestimation of rain rate in heavy rain. Velocities of raindrops can diverge from the assumed empirical fall speed in the presence of updrafts and downdrafts, causing an underestimation or overestimation of drop size (Salles and Creutin, 2003).

\subsection{2-D video disdrometer}

A 2-D video disdrometer (2DVD for short) comprises two light sources and two CCD line-scan cameras with $34.1 \mathrm{kHz}$ rate perpendicular to each other; two light sheets spaced $6.2 \mathrm{~mm}$ vertically form the virtual measurement area $(10 \mathrm{~cm} \times 10 \mathrm{~cm})$ (Kruger and Krajewski, 2002). Threedimensional shape information of particles can be recorded when they pass the sampling area, based on which the shape, size, volume, equivalent drop diameter, and oblateness can be calculated. The vertical velocity of each particle can be determined according to the distance between the two light sheets and its traveling time. The precipitation intensity, drop size distribution, and velocity distribution can be obtained 
by time integration (Schönhuber et al., 2007). The drops are sorted into 50 size intervals ranging from $0.1 \mathrm{~mm}$ to $9.9 \mathrm{~mm}$; the boundaries of the 50 channels are $0.2 \mathrm{~mm}$ uniformly.

The size resolution of 2DVD is 1 pixel of linear CCD or finer than $0.2 \mathrm{~mm}$; therefore, it cannot measure the drops smaller than $0.2 \mathrm{~mm}$. The enclosure of 2DVD can cause errors in the detection of small drops: some of them might be counted more than once when they pass across the measurement area while others are not counted at all (Nespor et al., 2000). Also the spatial distribution of raindrops crossing the measurement area could be distorted by the wind. A drop seen by the above light sheet might be matched to a different drop by the below light sheet. This mismatching could cause errors in shapes and velocities of particles (Leijnse and Uijlenhoet, 2010).

The instruments are presented in Fig. 1. The TBRG is installed on the ground, whereas ORG is installed on a $1.5 \mathrm{~m}$ tower. They are located near a Barrow meteorological tower; while PWD is installed at the $2 \mathrm{~m}$ level on the Barrow meteorological tower, JWD is installed on the ground next to the TBRG. The WRG is installed about $0.5 \mathrm{~m}$ above the ground with a wind screen. 2DVD is installed $1 \mathrm{~m}$ above the ground. They are located about 2-3 $\mathrm{m}$ apart in relation to the Barrow meteorological tower. It should be noted that the way the instruments are installed might not be optimal.

\section{Intercomparison analysis}

The rainfall measurements used in this study were collected during the Atmospheric Radiation Measurement (ARM) Climate Research that was operated at Darwin, Northern Territory, Australia, from January to October 2012. The rainfall observations are from a TBRG, a WRG, an ORG, a PWD, a JWD, and a 2DVD, whereas the DSDs are obtained from the JWD and 2DVD. Considering that different instruments have different time resolutions, the TBRG has a time resolution of $1 \mathrm{~min}$. We average the observation data from the other instruments over $1 \mathrm{~min}$ intervals, and analyze the details of different instrument performances minute by minute and event by event, from which different problems related to different instruments can be discussed.

\subsection{General analysis}

Table 1 presents the minutes of rainfall $\left(T_{\text {rain }}\right)$, max rain rate $\left(R_{\max }\right)$, and rainfall accumulations $\left(R_{\mathrm{acc}}\right)$ for 27 rainfall events observed by six instruments, of which the missing records and operational failures are excluded. In general, the maximum value of $T_{\text {rain }}$ was recorded by JWD and the maximum values of $R_{\max }$ and $R_{\mathrm{acc}}$ by PWD, while the minimum values of $T_{\text {rain }}$ and $R_{\max }, R_{\text {acc }}$ were recorded by WRG. The minutes of rainfall from TBRG and WRG are far fewer than those from ORG, PWD, JWD, and 2DVD, whereas there is no such obvious difference of rainfall accumulation from six instruments.

Table 2 presents the bias $(\Delta R)$ of total rainfall accumulations from six instruments, which can be calculated as

$\Delta R=\frac{R_{1}-R_{2}}{R_{1}}$,

where $R_{1}$ and $R_{2}$ denote the total rainfall accumulation of all 27 events from two instruments ( $R_{1}$ is the former one).

There are significant discrepancies in rainfall accumulations from different instruments: ORG presents the best agreement with the JWD $(\Delta R=0 \%)$; the ORG, JWD, and 2DVD present an excellent agreement with the TBRG $(\Delta R=5.9 \%, 5.8 \%,-4.8 \%)$, while the PWD and 2DVD present the worst agreement with the WRG (worse than $\pm 20 \%$ ). The comparisons of event rain amounts between TBRG and the other five instruments are presented in Fig. 2. The TBRG can record the rain amount precisely; therefore, the TBRG is used as a reference. The correlation coefficient and standard deviation $(\sigma)$ are used to quantity their discrepancies. It can be found that the ORG and TBRG have the best correlation coefficient and the least $\sigma$. The probable reason is that the ORG is calibrated by the TBRG, while the PWD and TBRG have the worst correlation coefficient and the largest $\sigma$. Compared with the TBRG, the WRG and ORG underestimated the rainfall accumulation obviously, while the PWD and 2DVD overestimated the rainfall accumulation significantly. However, bias does not quantify event-byevent agreement; details of specific rainfall events will be discussed in the following section.

\subsection{Event analysis}

Since general rain rate on the long term could not reflect the specific performance of each instrument, details of selected rainfall events with typical features during the precipitation process are discussed. In addition, differences and discrepancies between different instruments are analyzed in this section.

Figure $3 \mathrm{a}$ and $\mathrm{b}$ show the evolution of minute-byminute rain rate from six instruments on 13 January and 2 March 2012. It can be found that the TBRG, WRG, and ORG have a good agreement when rain rate is more than $20 \mathrm{~mm} \mathrm{~h}^{-1}$, whereas JWD records lower rain rate, while PWD and 2DVD record higher rain rates. The largest and the smallest rain rates are recorded by PWD and JWD respectively at the same time. The ORG, JWD, and 2DVD show a good agreement, whereas WRG records lower rain rate and PWD records a little higher rain rate when the rain rate is less than $20 \mathrm{~mm} \mathrm{~h}^{-1}$. Because the TBRG has a resolution of only $12 \mathrm{~mm} \mathrm{~h}^{-1}$, it takes a while to fill one tip of the compartment bucket with water during rainfall, especially for light rainfall, which causes the inability of the rainfall with the $R<12 \mathrm{~mm} \mathrm{~h}^{-1}$ to be detected in time. The rainfall duration 


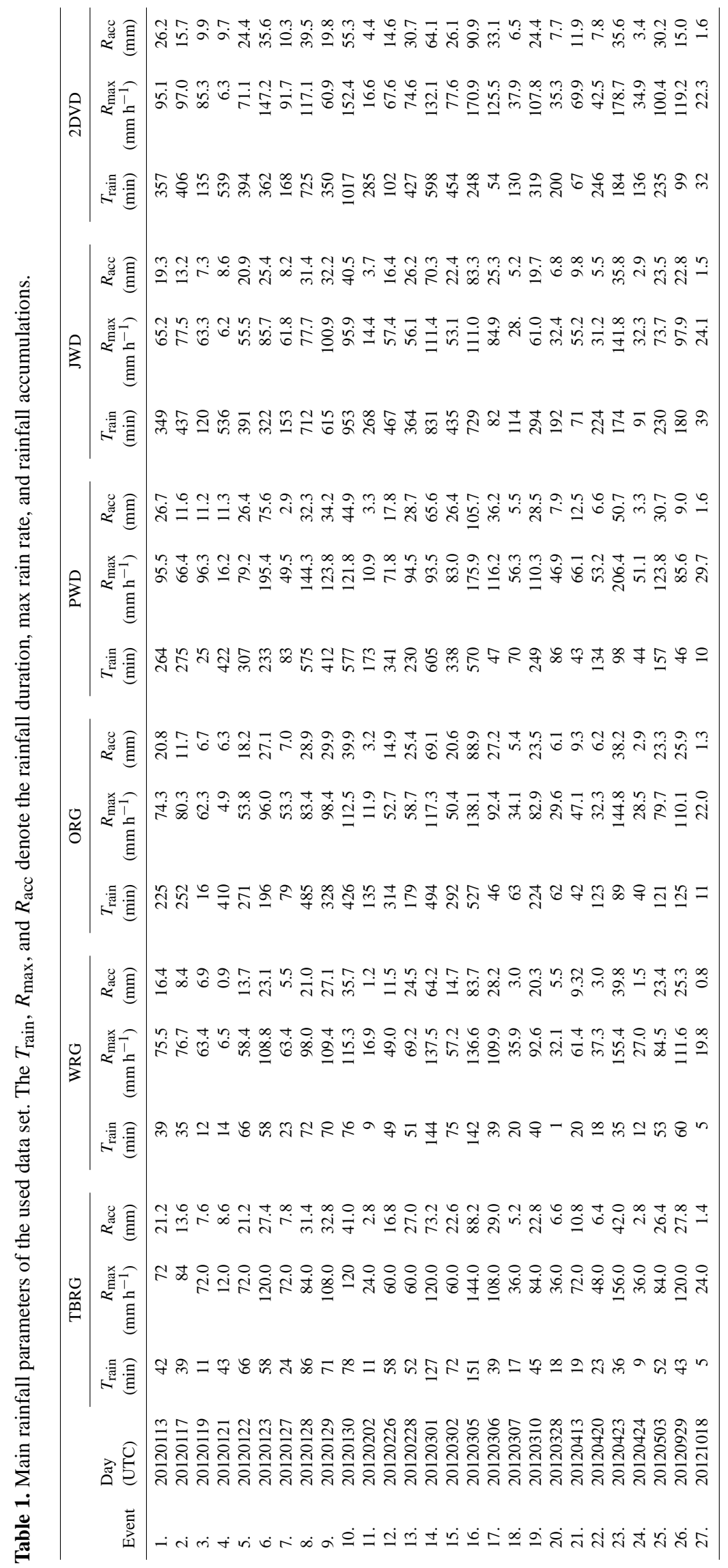




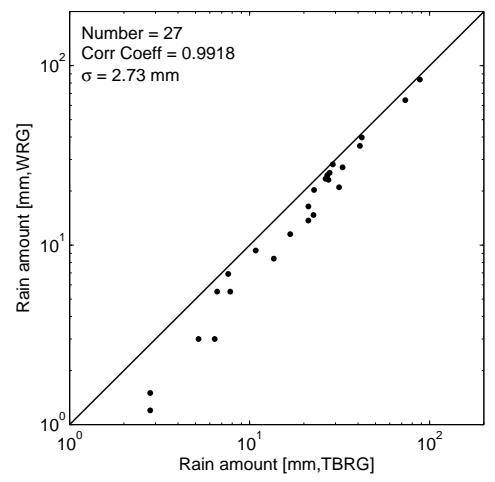

(a)

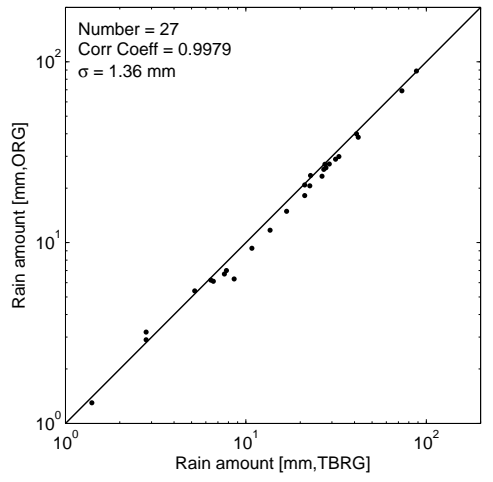

(b)

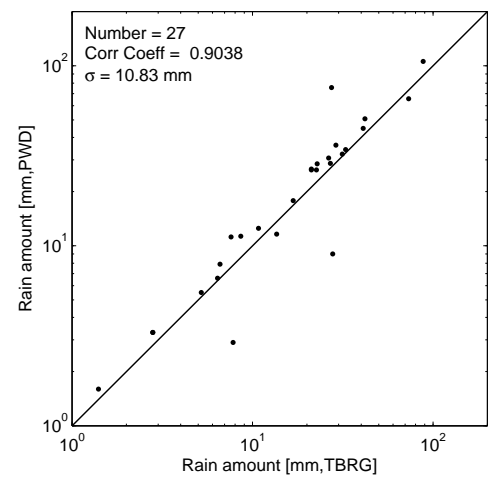

(c)

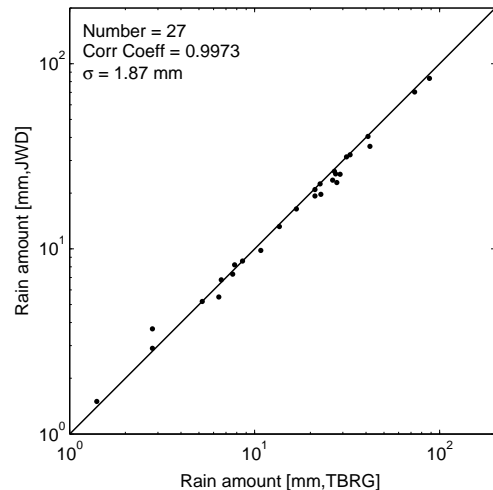

(d)

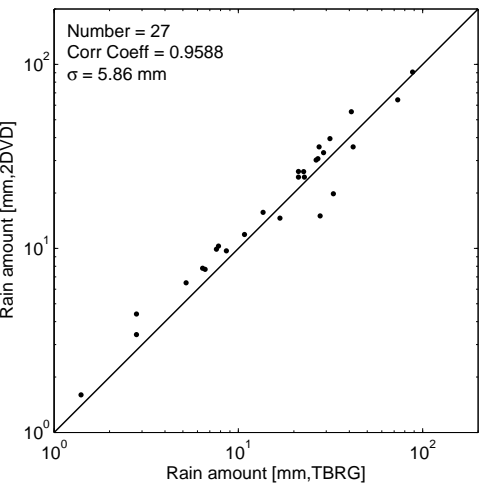

(e)

Fig. 2. Comparisons of event rain accumulations from six instruments. The Number, Corr Coeff, and $\sigma$ are the number of rainfall events, correlation coefficient, and standard deviation.

Table 2. Bias of total rainfall accumulations between six instruments.

\begin{tabular}{lrrrrrr}
\hline$\Delta R(\%)$ & TBRG & WRG & ORG & PWD & JWD & 2DVD \\
\hline TBRG & - & 16.9 & 5.9 & -14.8 & 5.8 & -4.8 \\
WRG & -20.4 & - & -13.4 & -38.3 & -13.4 & -26.2 \\
ORG & -6.2 & 11.7 & - & -21.9 & 0 & -11.3 \\
PWD & 12.9 & 27.7 & 18.0 & - & 18.0 & 8.7 \\
JWD & -6.1 & 11.8 & 0 & -21.9 & - & -11.3 \\
2DVD & 5.0 & 20.8 & 10.2 & -9.6 & 10.1 & - \\
\hline
\end{tabular}

recorded by TBRG is much less than the actual rainfall (the so-called timing error).

Although the variations of rain rate recorded by six instruments show great discrepancy, the rainfall accumulations from six instruments have relatively small biases. In Fig. 3a, the WRG has the smallest record of rainfall accumulation $(16.4 \mathrm{~mm})$, the PWD the largest record of rainfall accumulation $(26.6 \mathrm{~mm})$, and the TBRG, ORG, and JWD have a good agreement $(21.2 \mathrm{~mm}, 20.7 \mathrm{~mm}$, and $19.1 \mathrm{~mm})$, while the 2DVD has a bias a little higher $(26.0 \mathrm{~mm})$. The similar result can be found in Fig. 3b.

Here the rain rate from WRG is taken as a reference. The comparison of individual instruments against the WRG
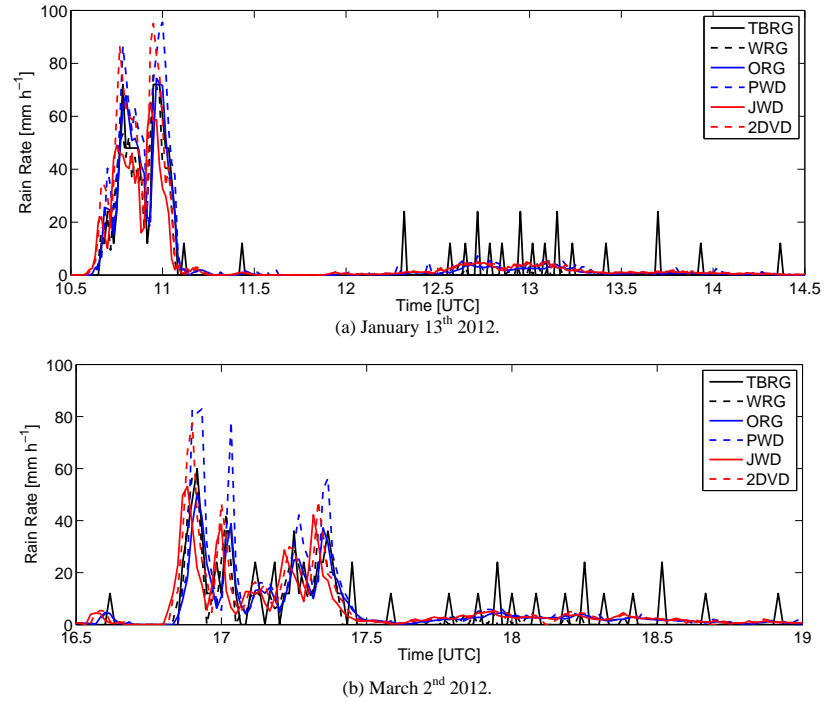

Fig. 3. Evolution of the rain rate recorded by six instruments.

values (13 January 2012) is shown in Fig. 4. The correlation coefficient and standard deviation $(\sigma)$ are used to quantity their discrepancies. The TBRG and WRG have the worst correlation coefficient; whereas the JWD and WRG have the 


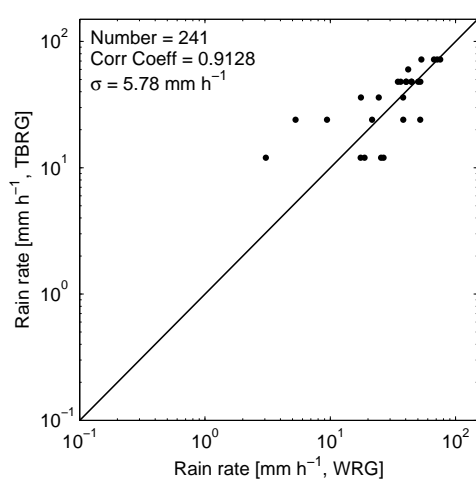

(a)

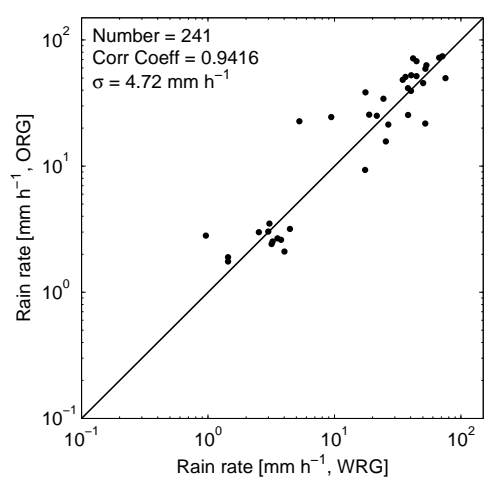

(b)

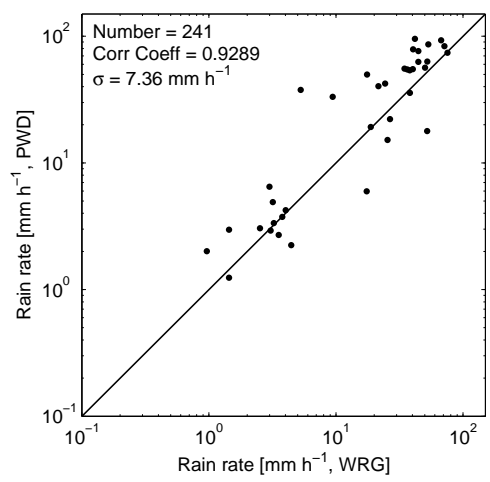

(c)

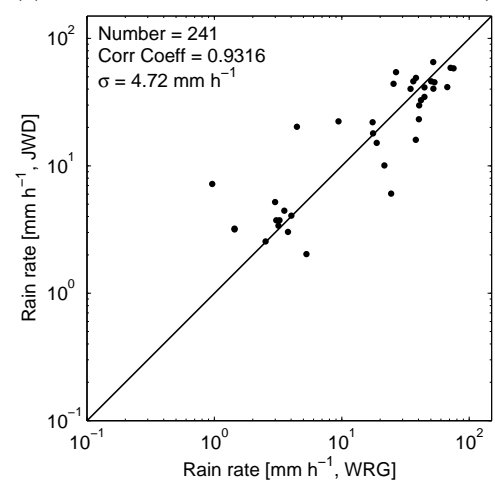

(d)

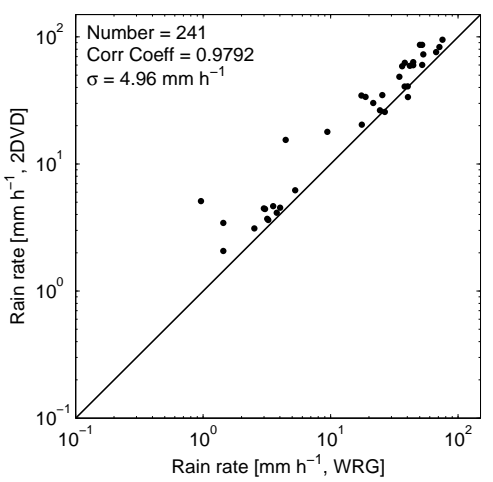

(e)

Fig. 4. Comparison of individual instruments against the WRG (13 January 2012). The Number, Corr Coeff, and $\sigma$ are the number of rainfall events minute by minute, correlation coefficient, and standard deviation.

largest $\sigma$. The rain rate from TBRG in Fig. 4a has the largest scatter, while rain rates from PWD, JWD, and 2DVD have a smaller scatter around the $1: 1$ line. Compared with the WRG values, the ORG underestimated the rainfall accumulation obviously. In general, the PWD and 2DVD overestimated, and the WRG and JWD underestimated the rain rate during heavy rainfall; the TBRG overestimated the rain rate obviously during light rainfall, while the WRG and ORG underestimated the rain rate slightly.

Figure 5 shows the variation of correlation coefficient of rain rate between the WRG and the other five instruments with the averaging interval. It can be found that the correlation coefficient increases obviously with the increasing of averaging interval, which indicates that the performance of instruments improves with the increasing averaging. The correlation coefficients between WRG and the other five instruments exceed 0.99 when the averaging interval is more than 30 min, in which WRG and ORG have the best correlation coefficient, and WRG and JWD have the worst correlation coefficient.

\subsection{DSD analysis}

Generally, the power-law parameters for Marshall and Palmer (MP; Smith et al., 1993) distributions are widely used for describing precipitation. However, the MP model applies

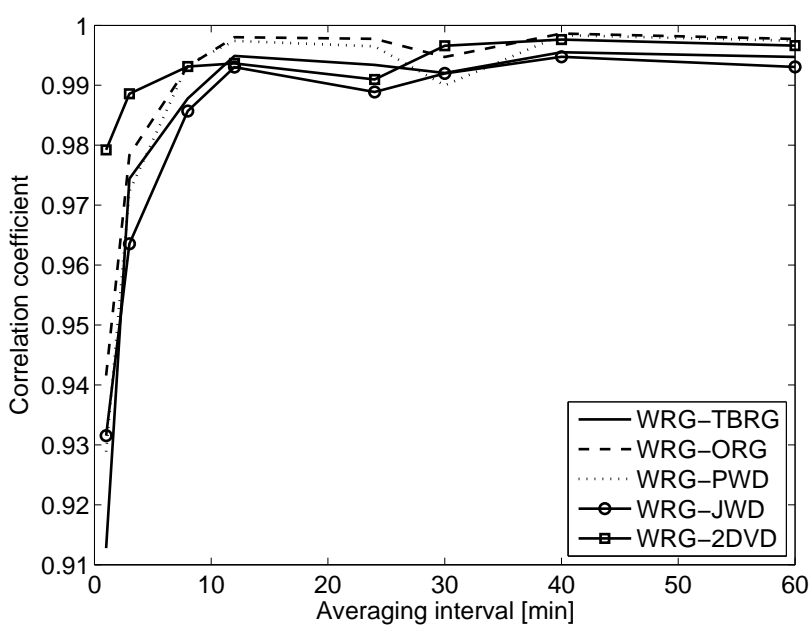

Fig. 5. Variation of correlation coefficient of rain rate between the WRG and the other five instruments with the averaging interval.

only to stable rainfall from stratiform clouds (Joss and Gori, 1987; Carbone and Nelson, 1978; Willis, 1984). It is now widely accepted that the DSDs of precipitation are better represented by the gamma distribution (Ulbrich, 1983; Testud et al., 2001): 


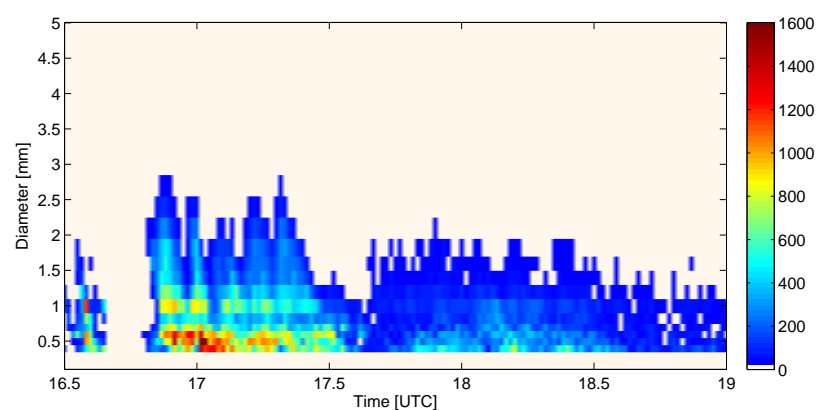

(a) Drop size distributions by JWD.

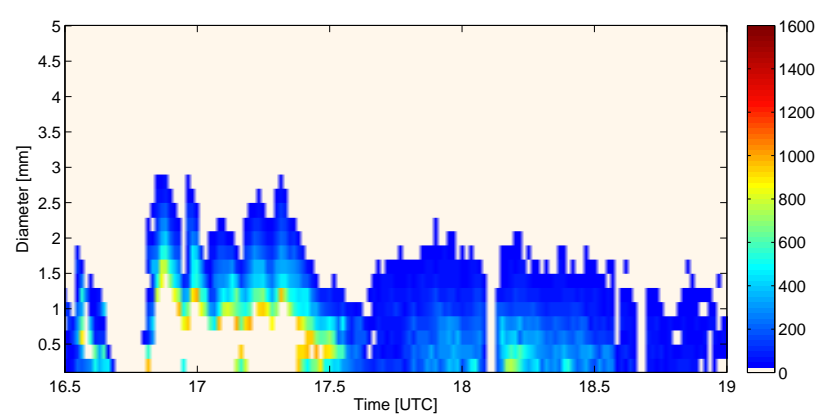

Fig. 6. Color display of the $1 \mathrm{~min}$ drop size distributions from JWD and 2DVD.

$N(D)=N_{0} D^{m} \exp (-\lambda D)$

where $N_{0}, m$, and $\lambda$ are intercept, shape, and slope parameters, which can be calculated by the method of moments (Tokay and Short, 1996). A correcting algorithm for the dead time of the JWD is used to correct the channel count of raindrops (Sheppard and Joe, 1994).

The $1 \mathrm{~min}$ drop size distributions observed by JWD and 2DVD are shown in Fig. 6. It should be noted that the minimum size of JWD is $0.3 \mathrm{~mm}$. Raindrops smaller than $0.3 \mathrm{~mm}$ cannot be measured by JWD, while the 2DVD can measure more small-size raindrops $(D<0.3 \mathrm{~mm})$ and large raindrops $(D>2.5 \mathrm{~mm})$ than JWD. There are obvious higher number concentrations of raindrops in the heavy rain $\left(R>20 \mathrm{~mm} \mathrm{~h}^{-1}\right)$. JWD measured fewer large-size drops $(D>2.5 \mathrm{~mm})$, and 2DVD measured obviously fewer smallsize drops $(D<1 \mathrm{~mm})$. Although the dead-time correction of JWD was applied, JWD is insensitive to the variation of kinetics of raindrops with size when $D>2.5 \mathrm{~mm}$, causing the underestimation of large raindrops. In the case of optical disdrometer, small raindrops in the absence of large raindrops can be recorded precisely by 2DVD; however, small raindrops in the more large-size raindrops might be easily omitted due to the shadow effect. Low counts of small raindrops in the heavy rainfall from 2DVD should be handled carefully.

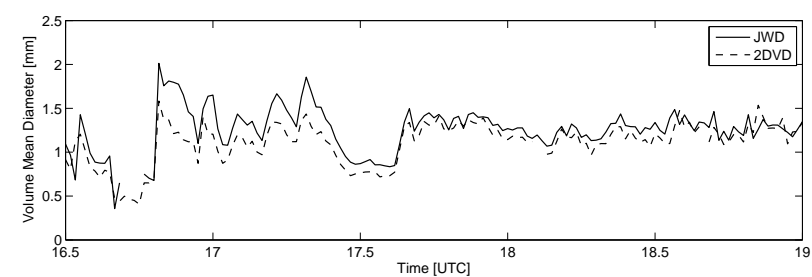

(a)

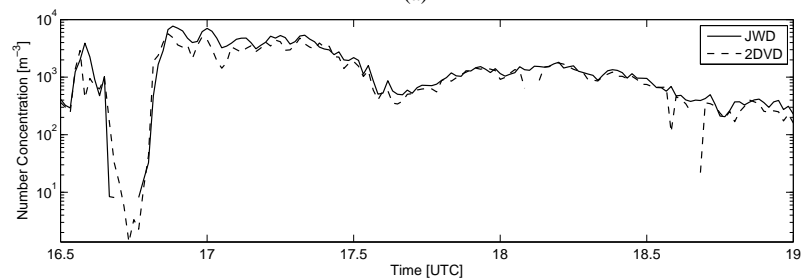

(b)

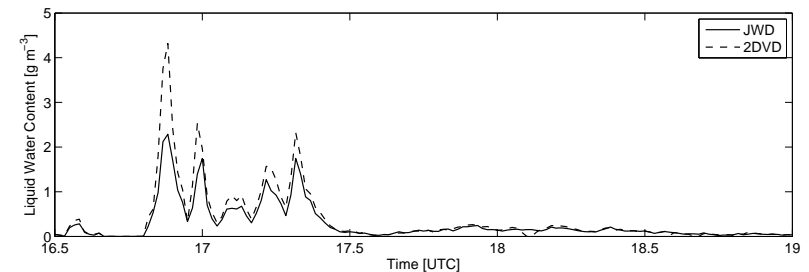

(c)

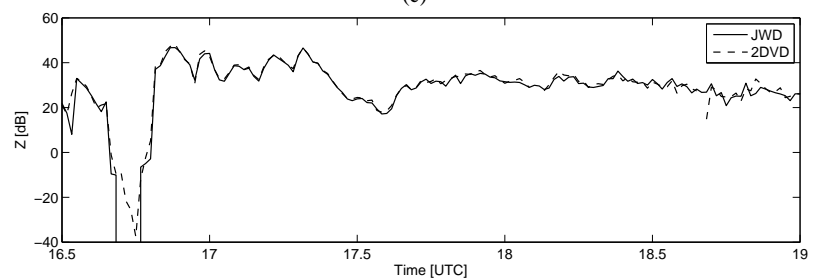

(d)

Fig. 7. Evolution of the rain variables on 2 March 2012.

The $x$ moment of DSD is defined as

$M_{x}=\int_{0}^{\infty} N(D) D^{x} \mathrm{~d} D=\sum_{i=1}^{N_{\text {class }}} N\left(D_{i}\right) D_{i}^{x} \Delta D_{i}$,

where $N_{\text {class }}$ is the number of diameter classes and $\Delta D_{i}$ is the diameter class width of class $i$.

The $N_{0}, m$, and $\Lambda$ can be calculated by using the $M_{3}, M_{4}$, and $M_{6}$ :

$\left\{\begin{array}{l}N_{0}=\frac{\lambda^{m+4} M_{3}}{\Gamma(m+4)} \\ m=\frac{11 G-8+\left(G^{2}+8 G\right)^{1 / 2}}{2(1-G)} \\ \lambda=\frac{m+4}{D_{m}},\end{array}\right.$

where $G=M_{4}^{3} /\left(M_{3}^{2} M_{6}\right), D_{m}=M_{4} / M_{3}$, and $\Gamma(m+4)$ is the gamma function with argument $m+4$. The number density $N_{d}$, liquid water content $W$, and radar reflectivity factor $Z$ of rainfall can be calculated by using the $M_{0}, M_{3}$, and $M_{6}$.

$\left\{\begin{array}{l}N_{d}=M_{0} \\ W=\frac{\pi \rho_{\text {water }}}{6} M_{3} \\ Z=M_{6},\end{array}\right.$ 
Table 3. Drop size distribution parameters and fitted general formulation of rainfall.

\begin{tabular}{lllllll}
\hline & $\alpha$ & $\beta$ & $x$ & $g(x)$ & $D_{0}-W$ & $D_{0}-R$ \\
\hline JWD & 0.1322 & 0.1435 & $\frac{D}{R^{0.1435}}$ & $70.78 x^{3.2} \exp (-13.38 x)$ & $D_{0}=0.1196 W^{0.2032}$ & $D_{0}=0.1187 R^{0.1435}$ \\
2DVD & 0.1452 & 0.1431 & $\frac{D}{R^{0.1431}}$ & $61.78 x^{5.65} \exp (-24.94 x)$ & $D_{0}=0.1224 W^{0.1994}$ & $D_{0}=0.1000 R^{0.1432}$ \\
\hline
\end{tabular}

where $\rho_{\text {water }}$ is the density of water.

Figure 7 shows the evolution of DSD variables minute by minute obtained by JWD and 2DVD on 2 March 2012. It can be found that the volume mean diameter and number concentration of raindrops measured by JWD is larger than that measured by 2DVD. The liquid water content measured by 2DVD is more than that by JWD, while there is little difference of $Z$ between JWD and 2DVD because of a logarithmic transformation. Considering the evolution of rain rate in Fig. 3b, the differences of volume mean diameter, number concentration, and liquid water content between both are becoming greater with the increasing rain rate.

Considering the variation of DSDs with different rainfall intensities (Willis and Tattelman, 1989), a general formulation of the DSD in terms of the diameter $D$ and the rain rate $R$ as a reference variable is used to analyze the DSDs (Sempere Torres et al., 1994, 1998):

$N(D, R)=R^{\alpha} g\left(D R^{-\beta}\right)$,

where $\alpha$ and $\beta$ are constants and $g(x)$ is the general distribution function, which is independent of $R$.

Figure 8 presents the scatterplot $N(D, R) R^{-\alpha}$ versus $D R^{-\beta}$ obtained by scaling experimental DSD in a semilogarithmic plot. A gamma shape is used to fit $g(x)$. The fitting method proposed by Sempere Torres et al. (1998) is used to fit the $\alpha, \beta, x, g(x)$, the relation between $D_{0}$ and $W$, and $D_{0}$ and $R$ from the experimental DSD data, which are shown in Table 3. It can be found that DSD parameters of JWD and 2DVD have a good agreement, except that there are certain discrepancies between the $g(x)$. The reason can be attributed to the obvious differences of the DSDs from JWD and 2DVD. Although the JWD can measure more small-size drops in a certain regime of raindrop size, the 2DVD has a larger measurement range (spectral width); raindrops smaller than $0.3 \mathrm{~mm}$ and larger than $2.5 \mathrm{~mm}$ can be recorded.

\section{Conclusions}

In order to evaluate the accuracy of rainfall measurements from different instruments based on different principles, we analyzed the rainfall observations from a tipping bucket rain gauge, a weighing bucket rain gauge, an optical rain gauge, a present weather detector, a Joss-Waldvogel disdrometer, and a 2-D video disdrometer. General rainfalls from January to October 2012 and selected rainfall events from six instruments were compared. DSDs observed by JWD and 2DVD

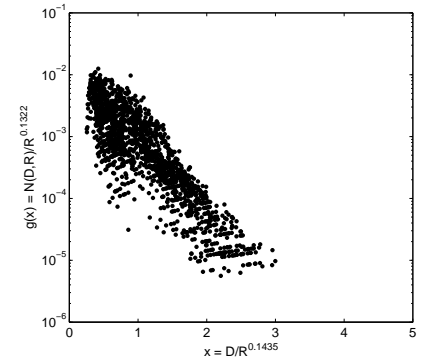

(a) JWD

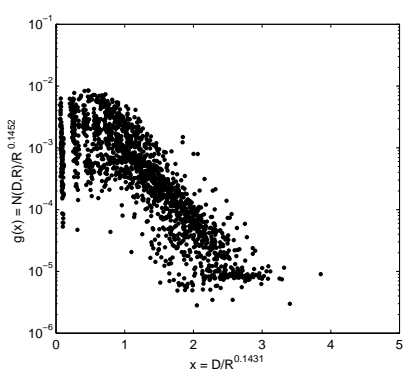

(b) 2DVD
Fig. 8. Experimental scattergram of the general function from JWD and 2DVD.

are compared and discussed. The results of the instrument comparisons can be used to address questions related to disdrometer application, measurement uncertainty, and remote sensing via weather radar.

For the long-term observations herein, there are different discrepancies in rain amounts from six instruments on the order of $0 \%$ to $27.7 \%$. When the rain rate is more than $20 \mathrm{~mm} \mathrm{~h}^{-1}$, the TBRG, WRG, and ORG have a good agreement, while the PWD and 2DVD record higher rain rates and JWD records a lower rain rate. When the rain rate was less than $20 \mathrm{~mm} \mathrm{~h}^{-1}$, the ORG agrees well with JWD and 2DVD, while the TBRG records a higher rain rate and WRG a lower rain rate. Optical and impact instruments are more sensitive to the light rainfall and small raindrops. Although there is a certain error in rainfall amount accumulation, their output of time series can reflect the temporal rainfall event precisely, which could be used for rainfall monitoring with better performances. A combination of TBRG/WRG and optical/impact instruments can compensate their shortcomings and promote the measurement of rain rate, rainfall amount, and rainfall duration.

Concerning the raindrop size distribution (DSD) parameters, the JWD agrees well with 2DVD for the overall rainfall. An empirical dead-time correction has been used to correct the DSDs from JWD in this study, but there are still obvious discrepancies. It should be noted that the 2DVD has a larger measurement range (spectral width) than JWD. Compared with the JWD, 2DVD can measure more smallsize raindrops $(D<0.3 \mathrm{~mm})$, large raindrops $(D>2.5 \mathrm{~mm})$, and fewer moderate-size raindrops $(0.3 \mathrm{~mm}<D<1.5 \mathrm{~mm})$. Small raindrops tend to be underestimated by 2DVD when $R>15 \mathrm{~mm} \mathrm{~h}^{-1}$. The possible reason is that the small 
raindrops tend to be omitted in more large-size raindrops due to the shadow effect of light. The 2DVD provides the most detailed information about the individual hydrometeors at present, but the measurement accuracy of small raindrops in the heavy rainfall from 2DVD should be handled carefully. There need to be more observations and further discussions on this issue in the following study.

There are many observations and comparisons of different instruments at present, but existing instruments have different shortcomings. The accurate measurement of precipitation is still one challenging task. In this study, simultaneous rainfall measurements of less than one year from multiple instruments are not sufficient; we still need to analyze longer term experiments and measurements with the same and different types of instruments. The effects of installation on measurement of different instruments are not taken into account, which might influence their performance. We will discuss this effect in our future research. Currently during the ARM, various instruments are now being operated at different climatic regions. Longer observations are expected to provide more rainfall and DSDs and allow us to evaluate the performances of multiple instruments for different rain intensities and different precipitation types.

Acknowledgements. This work is supported by the National Natural Science Foundation of China (Grant No. 41076118, and 41205125). Data were obtained from the Atmospheric Radiation Measurement (ARM) Program sponsored by the US Department of Energy, Office of Science, Office of Biological and Environmental Research, Climate and Environmental Sciences Division.

Edited by: P. Stammes

\section{References}

Baquero, M., Cruz-Pal, S., Bringi, V. N., and Chandrasekar, V.: Rain-Rate Estimate Algorithm Evaluation and Rainfall Characterization in Tropical Environments Using 2DVD, Rain Gauges and TRMM data, Geoscience and Remote Sensing Symposium, IGARSS '05. Proceedings, Seoul, Korea, 1146-1149, 2005.

Battaglia, A., Rustemeier, E., Tokay, A., Blahak, U., and Simmer, C.: PARSIVEL Snow Observations: A Critical Assessment, J. Atmos. Ocean. Tech., 27, 333-344, 2010.

Caracciolo, C., Natali, S., Prodi, F., and Tagliavini, A.: Comparison of two disdrometers based on different principles, 27th EGS Conference, Nice (France), 2002,

Carbone, R. E. and Nelson, L. D.: The evolution of raindrop spectra in warm-based convective storms as observed and numerically modelled, J. Atmos. Sci., 35, 2302-2314, 1978.

Chandrasekar, V. and Gori, E. G.: Multiple Disdrometer Observations of Rainfall, J. Appl. Meteorol., 30, 1514-1518, 1991.

Habib, E., Krajewski, W. F., and Kruger, A.: Sampling errors of tippingbucket rain gauge measurements, J. Hydrol. Eng., 6, 159$166,2001$.
Haij, M. D.: Automated discrimination of precipitation type using the FD12P present weather sensor: evaluation and opportunities, KNMI, R\&D Information and Observation Technology, 2007.

Joss, J. and Gori, E. G.: Shapes of Raindrop Size Distribution, J. Appl. Meteorol., 17, 1054-1061, 1987.

Joss, J. and Waldvogel, A.: Ein Spektrograph fur Niederschlagstrophen mit automatischer Auswertung, Pure Appl. Geophys, 68, 240-246, 1967.

Joss, J. and Waldvogel, A.: Comments on "Some Observations on the Joss-Waldvogel Rainfall Disdrometer”, J. Appl. Meteorol., 16, 112-113, 1977.

Kruger, A. and Krajewski, W. F.: Two-Dimensional Video Disdrometer: A Description, J. Atmos. Ocean. Tech., 19, 602-617, 2002.

Leijnse, H. and Uijlenhoet, R.: The effect of reported highvelocity small raindrops on inferred drop size distributions and derived power laws, Atmos. Chem. Phys., 10, 6807-6818, doi:10.5194/acp-10-6807-2010, 2010.

Löhnert, U., Kneifel, S., Battaglia, A., Hagen, M., Hirsch, L., and Crewell, S.: A multisensor approach toward a better understanding of snowfall microphysics: The TOSCA project, B. Am. Meteorol. Soc., 92, 613-628, 2011.

Lonnqvist, J. and Nylander, P.: A present weather instrument, Tech. Conf. on Instruments and Methods of Observation, , Austria, Vienna, WMO/TD-No. 462, 167-170, 1992.

Nespor, V., Krajewski, W. F., and Kruger, A.: Wind-induced error of raindrop size distribution measurement using a two-dimensional video disdrometer, J. Atmos. Ocean. Tech., 17, 1483-1492, 2000.

Nystuen, J. A.: Relative Performance of Automatic Rain Gauges under Different Rainfall Conditions, J. Atmos. Ocean. Tech., 16, 1025-1043, 1999.

Nystuen, J. A., Proni, J. R., Black, P. G., and Wilkerson, J. C.: A Comparison of Automatic Rain Gauges, J. Atmos. Ocean. Tech., 13, 62-73, 1996.

Present Weather Detector PWD22 User's Guide, M210543ENB: available at: http://www.vaisala.com/ (last access: December 2012), January 2004.

Salles, C. and Creutin, J.-D.: Instrumental Uncertainties in Z-R Relationships and Raindrop Fall Velocities, J. Appl. Meteorol., 42, 279-290, 2003.

Schönhuber, M., Lammer, G., and Randeu, W. L.: One decade of imaging precipitation measurement by $2 \mathrm{D}$-video-distrometer, Adv. Geosci., 10, 85-90, doi:10.5194/adgeo-10-85-2007, 2007.

Schuur, T. J., Ryzhkov, A. V., Zrnic, D. S., and Schönhuber, M.: Drop Size Distributions Measured by a 2D Video Disdrometer: Comparison with Dual-Polarization Radar Data, J. Appl. Meteorol., 40, 1019-1034, 2001.

Sempere Torres, D., Porrà, J. M., and Creutin, J.-D.: A general formulation for raindrop size distribution, J. Appl. Meteorol., 33, 1494-1502, 1994.

Sempere Torres, D., Porrà, J. M., and Creutin, J.-D.: Experimental evidence of a general description for raindrop size distribution properties, J. Geophys. Res., 103, 1785-1797, 1998.

Sheppard, B. E. and Joe, P. I.: Comparison of raindrop size distribution measurements by a joss-waldvogel disdrometer, a pms $2 \mathrm{dg}$ spectrometer, and a poss doppler radar, J. Atmos. Ocean. Tech., 11, 874-887, 1994.

Sieck, L. C., Burges, S. J., and Steiner, M.: Challenges in obtaining reliable measurements of point rainfall, Water Resour. Res., 43, 
W01420, doi:10.1029/2005WR004519, 2007.

Smith, P. L., Liu, Z., and Joss, J.: A study of sampling-variability effects in raindrop size observations, J. Appl. Meteorol., 32, 12591269, 1993.

Testud, J., Oury, S., Black, R. A., Ameyenc, P., and Xiankang, D.: The concept of "normalized" distribution to describe raindrop spectra: a tool for cloud physics and cloud remote sensing, J. Appl. Meteorol., 40, 1118-1140, 2001.

Thurai, M., Bringi, V. N., and Petersen, W. A.: Rain microstructure retrievals using 2-D video disdrometer and C-band polarimetric radar, Adv. Geosci., 20, 13-18, doi:10.5194/adgeo-20-13-2009, 2009.

Thurai, M., Petersen, W. A., Tokay, A., Schultz, C., and Gatlin, P.: Drop size distribution comparisons between Parsivel and 2-D video disdrometers, Adv. Geosci., 30, 3-9, doi:10.5194/adgeo30-3-2011, 2011.

Tokay, A. and Short, D. A.: Evidence from tropical raindrop spectra of the origin of rain from stratiform versus convective clouds, J. Appl. Meteorol., 35, 355-371, 1996.

Tokay, A., Kruger, A., and Krajewski, W. F.: Comparison of drop size distribution measurements by impact and optical disdrometers, J. Appl. Meteorol., 40, 2083-2097, 2001.
Tokay, A., Wolff, D. B., Wolff, K. R., and Bashor, P.: Rain gauge and disdrometer measurements during the keys area microphysics project (KAMP), J. Atmos. Ocean. Tech., 20, 14601477, 2003.

Tokay, A., Petersen, W., Gatlin, P., and Wingo, M.: Comparison of Raindrop Size Distribution Measurements by Collocated Disdrometers, J. Atmos. Ocean. Tech., online first, doi:10.1175/JTECH-D-12-00163.1, 2013.

Ulbrich, C. W.: Natural Variations in the Analytical Form of the Raindrop Size Distribution, J. Clim. Appl. Meteorol., 22, 1764 $1775,1983$.

Wang, J., Fisher, B. L., and Wolff, D. B.: Estimating Rain Rates from Tipping-Bucket Rain Gauge Measurements, J. Atmos. Ocean. Tech., 25, 43-56, 2008.

Willis, P. T.: Functional fits to some observed dropsize distributions and parameterization of rain, J. Atmos. Sci., 41, 1648-1661, 1984.

Willis, P. T. and Tattelman, P.: Drop-Size Distributions Associated with Intense Rainfall, J. Appl. Meteorol., 28, 3-15, 1989.

Wolff, D. B., Marks, D. A., Amitai, E., Silberstein, D. S., Fisher, B. L., Tokay, A., Wang, J., and Pippitt, J. L.: Ground validation for the Tropical Rainfall Measuring Mission (TRMM), J. Atmos. Ocean. Tech., 22, 365-380, 2005. 